\title{
Association of parental social support with energy balance-related behaviors in low- income and ethnically diverse children: a cross-sectional study
}

\author{
Natalia I. Heredia" ${ }^{*}$, Nalini Ranjit$^{2}$, Judith L. Warren ${ }^{3}$ and Alexandra E. Evans ${ }^{2}$
}

\begin{abstract}
Background: Parents play an important role in providing their children with social support for healthy eating and physical activity. However, different types of social support (e.g., instrumental, emotional, modeling, rules) might have different results on children's actual behavior. The purpose of this study was to assess the association of the different types of social support with children's physical activity and eating behaviors, as well as to examine whether these associations differ across racial/ethnic groups.
\end{abstract}

Methods: We surveyed 1169 low-income, ethnically diverse third graders and their caregivers to assess how children's physical activity and eating behaviors (fruit and vegetable and sugar-sweetened beverage intake) were associated with instrumental social support, emotional social support, modeling, rules and availability of certain foods in the home. We used sequential linear regression to test the association of parental social support with a child's physical activity and eating behaviors, adjusting for covariates, and then stratified to assess the differences in this association between racial/ ethnic groups.

Results: Parental social support and covariates explained 9-13\% of the variance in children's energy balance-related behaviors. Family food culture was significantly associated with fruit and vegetable and sugar-sweetened beverage intake, with availability of sugar-sweetened beverages in the home also associated with sugar-sweetened beverage intake. Instrumental and emotional support for physical activity were significantly associated with the child's physical activity. Results indicate that the association of various types of social support with children's physical activity and eating behaviors differ across racial/ethnic groups.

Conclusions: These results provide considerations for future interventions that aim to enhance parental support to improve children's energy balance-related behaviors.

Keywords: Social support, Physical activity, Nutrition, Minority populations, Child health

\section{Background}

Childhood obesity continues to be a significant problem in the United States. Approximately 34\% of children ages 611 are overweight or obese [1]. Low-income and minority children are disproportionately affected [2]; about $46 \%$ of Hispanics and 38\% of non-Hispanic Blacks ages 6-11 years

\footnotetext{
* Correspondence: natalia.i.heredia@uth.tmc.edu

${ }^{1}$ Center for Health Promotion and Prevention Research, The University of Texas Health Science Center at Houston (UTHealth) School of Public Health, 7000 Fannin St, Suite 2576E, Houston, TX 77030, USA

Full list of author information is available at the end of the article
}

old are overweight or obese, as compared to $29 \%$ of nonHispanic Whites [1]. Weight gain occurs when there is an imbalance between energy intake and energy expenditure. Lack of physical activity (PA) as well as overconsumption of energy-dense foods, such as sugar-sweetened beverages (SSB), can affect this balance and subsequent changes in body mass index (BMI) or adiposity [3-5]. These eating and PA behaviors are developed at a young age and typically track into adulthood, highlighting the need to address them earlier in the life span [6-9]. 
Parents' influence on children's PA and eating behaviors is exercised largely through the social support that they provide [10-15]. A variety of parental social support behaviors for children's eating and PA have been identified, including instrumental and emotional support, modeling, having rules, and certain foods being available or unavailable at home [16-19]. Instrumental social support refers to tangible behaviors, and is illustrated, for example, by parents helping their child select and prepare healthy snacks or helping them do physical activity [18, 20-22]. Emotional support is intangible and is evident when parents provide encouragement for eating healthy foods or engaging in PA $[23,24]$, and by demonstrating these behaviors themselves, parents model proper eating or exercise to their children $[17,25,26]$. Setting rules about healthy eating, for example, what or how much of a specific food the child may have, is another form of parental support that can influence behavior [27]. Lastly, ensuring that fruits and vegetables (FV) are readily available in the home and that SSB are not has been shown to be a significant predictor of healthy eating [17, 28-31]. Each type of social support serves a different role and the impact on behavior can vary across the different types [23, 32, 33]. A better understanding of how the different types of social support contribute to children's behaviors can help inform parenting practices and interventions targeting parenting practices [18, 23].

Although there is a wealth of research demonstrating associations between parental social support and children's energy-balance and related behaviors, little is known about these associations among low socioeconomic status (SES) and minority children [12, 34]. The identified link between parental social support and children's energy balancerelated behaviors may be different in low SES communities, given the important influence of the built and the food environments and their difference between high and low SES groups [35-38]. Although some studies have demonstrated that the relationship holds in low SES and minority groups [39-42], few researchers have investigated the relative importance of the various types of parental social support in these communities or have explicitly examined ethnic/racial differences [43, 44]. For example, Donnelly and Springer, found that social support was significantly associated with vegetable intake in Hispanic children; this association was not found in White or African-American children [42]. More research is needed on how the various types of parental social support are associated with PA and eating behaviors among low SES and minority children.

The purpose of this study was to assess the association of various types of parental social support with a child's PA and healthy eating in a sample of low SES, ethnically diverse third-grade students. Additionally, we determined how these associations varied across racial/ethnic categories. For this study, healthy eating was operationalized as more consumption of FV and less consumption of SSB. PA was operationalized as the number of times in the previous week children participated in sports, dance or played outdoor games during which they were very active.

\section{Methods}

This study was approved by the University of Texas Health Science Center (HSC-SPH-10-0733) and the Texas A\&M University Committees for the Protection of $\mathrm{Hu}$ man Subjects (2011-0012). The study was also approved by participating school districts' Review Committees. Parents provided their written consent to participate, as well as written consent to let their child participate in the study. Students provided written assent at the time of data collection as well.

\section{Study design}

This research examines the baseline data of the Texas Go! Eat! Grow! (TGEG) study of third-grade students and their parents in Texas. Additional details on the project and the protocol have been published elsewhere $[45,46]$. Briefly, the goal of the 5-year TGEG study was to assess the independent and combined impact of gardening, nutrition and PA interventions on the prevalence of healthy eating, PA, and obesity status among low-income, thirdgrade students.

Researchers recruited 28 schools in 5 geographically distinct areas in Central Texas that met the following inclusion criteria: 1) classified as a Title I school, 2) located within the study's geographical area, 3) were currently implementing the Coordinated Approach to Child Health program as a coordinated school wellness program [47, 48], 4) commitment at the district, principal, and teacher levels to participate, and 5) were willing to allow research staff to come into the school to recruit and collect data from thirdand fourth-grade students. Third-grade students at these schools were recruited at the start of the fall 2012 and 2013 school years (the intervention was implemented using a split cohort). Eligible students were enrolled as third-grade students in the participating school at the time of baseline data collection. Students were excluded if they had a special diet or if English or Spanish was not their primary language. Parents or primary caretakers of third-grade students were included as long as they were able to read English or Spanish. Researchers administered baseline questionnaires to the child and the parent/caregiver. Consenting parents completed questionnaires at home, while students completed their questionnaires in the classroom during school hours and were provided a small incentive, such as a lunch bag or water bottle. The baseline questionnaire was completed by 1326 third graders and 1206 parents. A total of 1169 parent-child dyads completed the questionnaire at baseline in fall 2012 and 2013. 


\section{Measures}

The study measures are described below. Table 1 provides additional details on Cronbach's $\alpha$ or Pearson's $r$ for the scales, response options, ranges, means and standard deviations for the social support variables. For all social support variables with more than one item, we calculated the scale score by multiplying the mean for the items in that variable by the number of items in that variable. All scales with 2 or more items demonstrated acceptable internal consistency $[49,50]$.

\section{Social support for healthy eating}

We assessed family food culture using a four-question scale specifically developed for this study that asked children the following: how often they eat breakfast, eat evening meals, go out to eat, and help prepare food with their families. We measured instrumental support for healthy eating using an adapted scale of seven questions from a previously validated measure that asked if parents did several different diet-related activities with their child the previous week, including buying vegetables that their child liked or helping their child make a snack that included vegetables [51].

Home availability and accessibility of FV was assessed by asking parents six questions about whether 100\% fruit juice, vegetable juice, fresh vegetables, frozen or dried vegetables, salad and cut-up fresh vegetables were available in the home during the previous week [29]. We assessed home availability of SSB with a single question asking parents how often soft-drinks or SSB were available in the home in the previous week.
We asked parents six questions to measure emotional support for healthy eating with example statements such as, "I show approval when my child eats what I want her/him to eat" and "I encourage my child to try new foods." Rules for healthy eating were assessed with three questions about parents' control of intake of sweets, high fat foods, and what the child eats away from home. We measured modeling of vegetable and SSB intake by asking parents how often their child saw them eating vegetables and drinking SSB.

\section{Social support for physical activity}

We assessed parental modeling of PA with one question that elicited how often the child sees the parent being active. We measured instrumental support for PA with two questions gauging how many days per week parents went for a walk or did other PA with their child and emotional support with four questions that determined how much they encourage, watch, and show approval for PA.

\section{Fruit and vegetable intake}

Children self-reported their FV intake using previously validated measures [52-54]. We asked them if they drank $100 \%$ fruit juice and if they ate fruit, orange vegetables, salads, or other vegetables during the previous day. We used a Likert-like scale for these questions with 0 indicating "No, I didn't eat/drink any of these yesterday" and 3 indicating "Yes, I ate/drank $\times 3$ or more times yesterday." We aggregated the responses to the five questions to determine the child's total FV intake the previous day.

Table 1 Main independent variables

\begin{tabular}{|c|c|c|c|c|c|c|c|c|}
\hline Source & Variable & \# Items & Response options & Cronbach's a & Pearson's r & $\begin{array}{l}\text { Potential } \\
\text { Range }\end{array}$ & $\begin{array}{l}\text { Actual } \\
\text { Range }\end{array}$ & Mean (SD) \\
\hline & \multicolumn{8}{|l|}{ Social Support for Healthy Eating } \\
\hline Child & Family Food Culture & 4 & $\begin{array}{l}0 \text { (Never or almost never) to } 2 \\
\text { (almost always or always) }\end{array}$ & .64 & NA & $0-8$ & $0-8$ & $5.36(1.80)$ \\
\hline Parent & $\begin{array}{l}\text { Instrumental support for } \\
\text { healthy eating }\end{array}$ & 7 & 0 (No) to 1 (Yes) & .76 & NA & $0-7$ & $0-7$ & $4.38(2.04)$ \\
\hline Parent & $\begin{array}{l}\text { Home availability and } \\
\text { accessibility of FV }\end{array}$ & 6 & 0 (Never) to 3 (All of the time) & .72 & NA & $0-18$ & $1-18$ & $10.75(3.57)$ \\
\hline Parent & Home availability of SSB & 1 & 0 (Never) to 3 (All of the time) & NA & NA & $0-3$ & $0-3$ & $1.59(.87)$ \\
\hline Parent & $\begin{array}{l}\text { Emotional support for healthy } \\
\text { eating }\end{array}$ & 6 & $\begin{array}{l}0 \text { (Strongly disagree) to } 4 \\
\text { (Strongly agree) }\end{array}$ & .71 & NA & $0-24$ & $0-24$ & $17.66(3.82)$ \\
\hline Parent & Rules for healthy eating & 3 & $\begin{array}{l}0 \text { (Strongly disagree) to } 4 \\
\text { (Strongly agree) }\end{array}$ & .77 & NA & $0-12$ & $0-12$ & $8.96(2.46)$ \\
\hline Parent & Modeling vegetable intake & 1 & 0 (Never) to 4 (About once a day) & NA & NA & $0-4$ & $0-4$ & $3.48(.84)$ \\
\hline \multirow[t]{2}{*}{ Parent } & Modeling SSB & 1 & 0 (Never) to 4 (About once a day) & NA & NA & $0-4$ & $0-4$ & $2.79(1.18)$ \\
\hline & \multicolumn{8}{|l|}{ Social Support for Physical Activity } \\
\hline Parent & Instrumental support for PA & 2 & 0 (Never) to 7 (7 days) & NA & .46 & $0-14$ & $0-14$ & $3.96(3.38)$ \\
\hline Parent & Emotional support for PA & 4 & $\begin{array}{l}0 \text { (Strongly disagree) to } 4 \\
\text { (Strongly agree) }\end{array}$ & .74 & NA & $0-16$ & $0-16$ & $12.73(2.52)$ \\
\hline Parent & Modeling PA & 1 & 0 (Never) to 4 (About once a day) & NA & NA & $0-4$ & $0-4$ & $3.55(.82)$ \\
\hline
\end{tabular}




\section{Sugar-sweetened beverage intake}

Children self-reported their SSB intake in two questions, 1) if they had consumed any punch, Kool-Aid, sports drinks, or other fruit flavored drinks the previous day and 2) if they drank any regular sodas or soft drinks the previous day. Answers were on a Likert-like scale with 0 indicating "No, I didn't drink any of these yesterday" and 3 indicating "Yes, I drank $\times 3$ or more times yesterday." We aggregated the responses to get the child's total SSB intake for the previous day.

\section{Physical activity}

Parents reported how many times in the previous week their child engaged in sports, dance or outdoor play, outside of school. Response options ranged from 0 indicating "None" to 4 indicating "6 or more times."

\section{Demographics}

Children self-reported their age and gender; parents selfreported their gender, relationship to the child, age, race, ethnicity, employment status, highest level of education, and marital status. Food insecurity was measured on a scale from "almost always" to "almost never or never" by asking parents "How often do you run out of food before the end of the month because you can't afford to buy more?" [55]. Parents were asked what language was spoken at home with answer choices of English, Spanish, or Other. They were also asked if the family received federal benefits, such as the Supplemental Nutrition Assistance Program (SNAP) and The Special Supplemental Nutrition Assistance Program for Women, Infants, and Children (WIC), and whether their child received a free or reduced-cost school lunch.

\section{Anthropometric measures}

Height and weight were collected during school site visits by two project staff members who were trained by the program director and certified for essential skills [45]. Height was measured using the Perspective Enterprise Model PE-AIM-10 stadiometers and weight using the Tanita scale model BWB-800S. BMI was calculated from height and weight data, and the students were placed into BMI categories using growth charts from the Centers for Disease Control and Prevention [56].

\section{Data analysis}

Preliminary descriptive analyses were conducted by examining frequency distributions of key demographic variables in the sample. The levels of the different types of parental social support for eating and PA behavior were compared across the demographic categories (gender, BMI, race/ethnicity) of children using independent samples $t$-test or one-way ANOVA, as appropriate. We then used sequential linear regression with listwise deletion to assess the relationship between social support variables and FV intake,
SSB intake, and PA, while controlling for important covariates, including race/ethnicity variables, gender, BMI zscore, food security, receiving free or reduced-cost lunch, and parental education [57-59]. For all three energy balance outcomes, we entered child's gender, BMI, race/ethnicity, receiving free or reduced-cost lunch, and parental education into step 1 , food insecurity into step 2 , and the social support variables into step 3 . The threshold for significance was set at $p<.05$.

\section{Results}

\section{Sample characteristics}

There were 1169 parent-child dyads included in this study (Table 2). Children were third-grade students in Texas, between the ages of 7 and 11 . Students were $42 \%$ female, 33\% Hispanic, and $74 \%$ received free or reduced-cost lunch. Of the parents and caregivers, $83 \%$ were female. Almost 92\% of caregivers indicated they were a parent, while $5 \%$ indicated they were a grandparent or other caregiver, and 3\% were missing (not shown in table). About $51 \%$ of parents had a high school diploma, GED, or less education. In our sample, $42 \%$ of families indicated that they received SNAP, $12 \%$ received WIC, and $41 \%$ said that the family sometimes or almost always experienced food insecurity.

\section{Level of parental support by sex, race/ethnicity, and weight status}

There was a significant difference between boys and girls for family food culture and instrumental support for healthy eating, with girls having a higher mean for both (Table 3). There were also significant differences between racial/ethnic groups for home availability and accessibility of FV, emotional support for healthy eating, rules for eating, modeling of vegetable intake and modeling SSB intake (Table 3). Black children had a higher mean for home availability and accessibility of FV and rules for eating compared to the other three groups. White children had the highest mean for emotional support for healthy eating and modeling of vegetable intake, while Hispanic children had the highest mean for modeling SSB intake. Lastly, there were also significant differences by child's weight status for emotional support for healthy eating and modeling of vegetable intake (Table 3). Interestingly, overweight children had the highest mean for emotional support for healthy eating and normal weight children had the highest mean for modeling of vegetable intake.

\section{Associations between parental social support and healthy eating}

After adjusting for covariates the sequential regression showed that of the social support variables, only family food culture was significantly associated with FV intake (Table 4). BMI z-score and receiving free or reduced-cost lunch were also significantly associated with FV intake. 
Table 2 Participant demographics, full sample

\begin{tabular}{|c|c|c|}
\hline & Number & Percent \\
\hline Child demographics & 1169 & 100 \\
\hline \multicolumn{3}{|l|}{ Gender } \\
\hline Male & 495 & 42.3 \\
\hline Female & 492 & 42.1 \\
\hline Missing & 182 & 15.6 \\
\hline \multicolumn{3}{|l|}{ Age } \\
\hline 7 years old & 6 & .5 \\
\hline 8 years old & 672 & 57.5 \\
\hline 9 years old & 269 & 23.0 \\
\hline 10 years old & 24 & 2.0 \\
\hline 11 years old & 3 & .3 \\
\hline Missing & 195 & 16.7 \\
\hline \multicolumn{3}{|l|}{ Race/Ethnicity } \\
\hline White & 209 & 17.9 \\
\hline Black & 179 & 15.3 \\
\hline Hispanic & 385 & 32.9 \\
\hline Other & 204 & 17.5 \\
\hline Missing & 192 & 16.4 \\
\hline \multicolumn{3}{|l|}{ Weight status } \\
\hline Underweight & 27 & 2.3 \\
\hline Normal Weight & 466 & 39.9 \\
\hline Overweight & 171 & 14.6 \\
\hline Obese & 270 & 23.1 \\
\hline Missing & 235 & 20.1 \\
\hline Parent demographics & 1169 & 100 \\
\hline \multicolumn{3}{|l|}{ Gender } \\
\hline Male & 132 & 11.3 \\
\hline Female & 970 & 83.0 \\
\hline Missing & 67 & 5.7 \\
\hline \multicolumn{3}{|l|}{ Age } \\
\hline Less than 30 & 219 & 18.8 \\
\hline 30 to 34 & 336 & 28.7 \\
\hline 35 to 39 & 211 & 18.0 \\
\hline 40 and above & 246 & 21.1 \\
\hline Missing & 157 & 13.4 \\
\hline \multicolumn{3}{|l|}{ Employment status } \\
\hline Full-time & 557 & 47.7 \\
\hline Part-time & 157 & 13.4 \\
\hline No work outside the home & 372 & 31.8 \\
\hline Retried & 13 & 1.1 \\
\hline Missing & 70 & 6.0 \\
\hline \multicolumn{3}{|l|}{ Education } \\
\hline Less than 12 years & 231 & 19.8 \\
\hline High school or GED & 360 & 30.8 \\
\hline
\end{tabular}

Table 2 Participant demographics, full sample (Continued)

\begin{tabular}{|c|c|c|}
\hline Trade/Tech college & 100 & 8.5 \\
\hline Some college & 206 & 17.6 \\
\hline College or advanced degree & 173 & 14.8 \\
\hline Missing & 99 & 8.5 \\
\hline \multicolumn{3}{|l|}{ Marital status } \\
\hline Married & 634 & 54.2 \\
\hline Separated or Divorced & 178 & 15.2 \\
\hline Single, never married & 264 & 22.6 \\
\hline Widowed & 25 & 2.2 \\
\hline Missing & 68 & 5.8 \\
\hline Family demographics & 1169 & 100 \\
\hline \multicolumn{3}{|l|}{ Language spoken at home } \\
\hline English & 786 & 67.2 \\
\hline Spanish & 295 & 25.2 \\
\hline Other & 16 & 1.4 \\
\hline Missing & 72 & 6.2 \\
\hline \multicolumn{3}{|l|}{ Food insecurity } \\
\hline Almost never or never & 625 & 53.5 \\
\hline Sometimes & 331 & 28.3 \\
\hline Almost always & 152 & 13.0 \\
\hline Missing & 61 & 5.2 \\
\hline \multicolumn{3}{|l|}{ Child receives free or reduced lunch } \\
\hline Yes & 861 & 73.7 \\
\hline No & 240 & 20.5 \\
\hline Missing & 68 & 5.8 \\
\hline \multicolumn{3}{|l|}{ SNAP recipients } \\
\hline Yes & 494 & 42.3 \\
\hline No & 591 & 50.5 \\
\hline Missing & 84 & 7.2 \\
\hline \multicolumn{3}{|l|}{ WIC recipients } \\
\hline Yes & 140 & 12.0 \\
\hline No & 945 & 80.8 \\
\hline Missing & 84 & 7.2 \\
\hline
\end{tabular}

For SSB intake, both family food culture and home availability of those beverages were significantly associated with their intake, as were gender and free or reduced-cost lunch (Table 5). The social support variables and sociodemographic covariates explained about $13 \%$ of the variance in FV intake and 9\% of the variance in SSB intake.

\section{Associations between parental social support and physical activity}

After adjusting for covariates, both instrumental and emotional support for PA were significantly associated with the child's PA (Table 6). The social support variables and the sociodemographic covariates explained 
Table 3 Level of parental social support for eating and physical activity behavior by group

\begin{tabular}{|c|c|c|c|c|c|c|c|c|c|c|c|}
\hline & $\begin{array}{l}\text { Family } \\
\text { Food } \\
\text { Culture }\end{array}$ & $\begin{array}{l}\text { Instrumental support } \\
\text { for healthy eating }\end{array}$ & $\begin{array}{l}\text { Home availability/ } \\
\text { accessibility of FV }\end{array}$ & $\begin{array}{l}\text { Home availability } \\
\text { of SSB }\end{array}$ & $\begin{array}{l}\text { Emotional support } \\
\text { for healthy eating }\end{array}$ & $\begin{array}{l}\text { Rules for } \\
\text { eating }\end{array}$ & $\begin{array}{l}\text { Modeling } \\
\text { vegetable intake }\end{array}$ & $\begin{array}{l}\text { Modeling } \\
\text { SSB intake }\end{array}$ & $\begin{array}{l}\text { Instrumental } \\
\text { support for PA }\end{array}$ & $\begin{array}{l}\text { Emotional } \\
\text { support for PA }\end{array}$ & $\begin{array}{l}\text { Modeling } \\
\text { of PA }\end{array}$ \\
\hline & $N=977$ & $N=1148$ & $N=1164$ & $N=1151$ & $N=1146$ & $N=1145$ & $N=1143$ & $N=1139$ & $N=1139$ & $N=1127$ & $N=1144$ \\
\hline $\begin{array}{l}\text { Boys, Mean } \\
\text { (SD) }\end{array}$ & $5.23(1.86)$ & $4.13(2.03)$ & $10.56(3.63)$ & $1.58(.86)$ & $17.46(3.88)$ & $8.91(2.42)$ & $3.47(.82)$ & $2.80(1.17)$ & $3.86(3.26)$ & $12.84(2.50)$ & $3.54(.81)$ \\
\hline $\begin{array}{l}\text { Girls, Mean } \\
\text { (SD) }\end{array}$ & $5.48(1.73)$ & $4.60(1.99)$ & $10.81(3.56)$ & $1.59(.88)$ & $17.68(3.77)$ & $8.95(2.48)$ & $3.49(.80)$ & $2.75(1.23)$ & $4.02(3.32)$ & $12.63(2.52)$ & $3.55(.81)$ \\
\hline$t^{a}$ & $-2.18^{*}$ & $-3.59 * * *$ & -1.09 & -.24 & -.91 & -.24 & -.28 & .71 & -.743 & 1.27 & -.17 \\
\hline $\begin{array}{l}\text { White, Mean } \\
\text { (SD) }\end{array}$ & $5.12(1.79)$ & $4.30(1.94)$ & $10.90(3.26)$ & $1.64(.90)$ & $18.24(3.13)$ & $8.68(2.33)$ & $3.65(.69)$ & $2.73(1.28)$ & $3.53(3.07)$ & $12.98(2.35)$ & $3.60(.66)$ \\
\hline $\begin{array}{l}\text { Black, Mean } \\
\text { (SD) }\end{array}$ & $5.53(2.00)$ & $4.44(1.89)$ & $11.57(3.70)$ & $1.62(.86)$ & $17.96(3.70)$ & $9.30(2.49)$ & $3.61(.66)$ & $2.66(1.14)$ & $4.14(3.58)$ & $13.02(2.49)$ & 3.51 (.87) \\
\hline $\begin{array}{l}\text { Hispanic, Mean } \\
\text { (SD) }\end{array}$ & $5.46(1.74)$ & $4.42(2.12)$ & $10.29(3.69)$ & $1.54(.82)$ & $16.99(4.15)$ & $8.79(2.43)$ & $3.36(.86)$ & $2.92(1.12)$ & $4.14(3.24)$ & $12.51(2.51)$ & $3.55(.86)$ \\
\hline $\begin{array}{l}\text { Other, Mean } \\
\text { (SD) }\end{array}$ & $5.26(1.68)$ & $4.30(2.04)$ & $10.43(3.47)$ & $1.58(.95)$ & 17.65 (3.79) & $9.12(2.55)$ & $3.42(.91)$ & $2.62(1.28)$ & $3.92(3.33)$ & $12.69(2.65)$ & $3.50(.81)$ \\
\hline$F^{b}$ & 2.40 & .31 & $5.84^{* *}$ & .77 & $5.72^{* *}$ & $2.88^{*}$ & $7.78^{* * *}$ & $3.77^{*}$ & 1.71 & 2.46 & .73 \\
\hline $\begin{array}{l}\text { Under weight, } \\
\text { Mean (SD) }\end{array}$ & $5.30(1.66)$ & $4.33(2.00)$ & $11.31(3.81)$ & $1.59(1.05)$ & 17.98 (3.08) & $9.46(2.48)$ & $3.42(.95)$ & $2.67(1.21)$ & $4.15(3.76)$ & $12.87(2.45)$ & $3.44(.85)$ \\
\hline $\begin{array}{l}\text { Normal weight, } \\
\text { Mean (SD) }\end{array}$ & $5.49(1.82)$ & $4.51(2.03)$ & $10.77(3.54)$ & $1.55(.88)$ & $17.79(3.76)$ & $9.06(2.43)$ & $3.56(.74)$ & $2.81(1.18)$ & $4.13(3.37)$ & $12.73(2.52)$ & $3.59(.78)$ \\
\hline $\begin{array}{l}\text { Overweight, } \\
\text { Mean (SD) }\end{array}$ & $5.32(1.83)$ & $4.40(1.94)$ & $10.89(3.54)$ & $1.69(.87)$ & $18.02(3.88)$ & $8.82(2.64)$ & $3.47(.80)$ & $2.78(1.18)$ & $3.77(3.46)$ & $13.13(2.47)$ & $3.56(.81)$ \\
\hline $\begin{array}{l}\text { Obese, Mean } \\
\text { (SD) }\end{array}$ & $5.36(1.78)$ & $4.08(2.07)$ & $10.34(3.75)$ & $1.55(.81)$ & $16.82(3.85)$ & $8.82(2.36)$ & $3.38(.92)$ & $2.73(1.24)$ & $3.79(3.01)$ & $12.52(2.52)$ & $3.47(.88)$ \\
\hline$F^{b}$ & .13 & 2.48 & 1.38 & 1.23 & $4.77^{* *}$ & 1.08 & $2.82^{*}$ & .29 & .88 & 1.95 & 1.36 \\
\hline
\end{tabular}

Note: ${ }^{*} p<0.05, * * p<0.01,{ }^{* * *} p<0.001$

andependent-samples $t$-test, ${ }^{\text {b }}$ One-way ANOVA 
Table 4 Sequential regression analysis for association of social support with FV intake

\begin{tabular}{|c|c|c|c|c|c|}
\hline & $B$ & SEB & $\beta$ & $R^{2}$ & $R^{2}$ change \\
\hline Step 1 & & & & $.055^{* * *}$ & $.055^{* * *}$ \\
\hline Gender & -.413 & .265 & -.054 & & \\
\hline BMI z-score & .306 & .109 & $.097^{* *}$ & & \\
\hline Receive free or reduced lunch & .949 & .38 & $.104^{*}$ & & \\
\hline Parent's education & -.184 & .101 & -.072 & & \\
\hline Black & .779 & .435 & .078 & & \\
\hline Hispanic & .167 & .385 & .021 & & \\
\hline Other & .723 & .411 & .077 & & \\
\hline Step 2 & & & & $.055^{* * *}$ & .000 \\
\hline Food insecurity & .158 & .287 & .021 & & \\
\hline Step 3 & & & & $.128^{* * *}$ & $.073^{* * *}$ \\
\hline Family food culture & .5597 & .074 & $.259^{* * *}$ & & \\
\hline Instrumental support for healthy eating & .037 & .073 & .020 & & \\
\hline Home availability/accessibility of FV & .057 & .044 & .053 & & \\
\hline Home availability of SSB & -.165 & .171 & -.038 & & \\
\hline Emotional support for healthy eating & -.036 & .039 & -.036 & & \\
\hline Rules for eating & -.076 & .062 & -.050 & & \\
\hline Modeling of vegetable intake & -.068 & .176 & -.014 & & \\
\hline Modeling of SSB intake & -.040 & .124 & -.012 & & \\
\hline
\end{tabular}

Note: $B=$ Unstandardized beta coefficient; $S E B=$ Standard error for $B ; \beta=$ Standardized beta coefficient; $R^{2}=$ adjusted R-square; ${ }^{*} p<0.05 ;{ }^{* *} p<0.01 ;{ }^{* * *} p<0.001$

Table 5 Sequential regression analysis for association of social support with SSB intake

\begin{tabular}{|c|c|c|c|c|c|}
\hline & $B$ & SE B & $\beta$ & $R^{2}$ & $R^{2}$ change \\
\hline Step 1 & & & & $.053^{* * *}$ & $.053^{* * *}$ \\
\hline Male & -.457 & .124 & $-.130 * * *$ & & \\
\hline BMI z-score & -.003 & .051 & -.002 & & \\
\hline Receive free or reduced lunch & .367 & .180 & $.088^{*}$ & & \\
\hline Parent's education & -.074 & .047 & -.063 & & \\
\hline Black & .405 & .205 & $.087^{*}$ & & \\
\hline Hispanic & .091 & .180 & .025 & & \\
\hline Other & .050 & .191 & .012 & & \\
\hline Step 2 & & & & $.056^{* * *}$ & .003 \\
\hline Food insecurity & .171 & .135 & .048 & & \\
\hline Step 3 & & & & $.086^{* * *}$ & $.030^{* *}$ \\
\hline Family food culture & .098 & .035 & $.098^{* *}$ & & \\
\hline Instrumental support for healthy eating & .052 & .034 & .061 & & \\
\hline Home availability/accessibility of FV & -.002 & .021 & -.004 & & \\
\hline Home availability of SSB & .187 & .080 & $.093^{* *}$ & & \\
\hline Emotional support for healthy eating & .012 & .018 & .025 & & \\
\hline Rules for eating & -.035 & .029 & -.049 & & \\
\hline Modeling of vegetable intake & -.114 & .082 & -.053 & & \\
\hline Modeling of SSB intake & .028 & .058 & .019 & & \\
\hline
\end{tabular}

Note: $B=$ Unstandardized beta coefficient; $S E B=$ Standard error for $B ; \beta=$ Standardized beta coefficient; $R^{2}=$ adjusted R-square; ${ }^{*} p<.05 ;{ }^{* *} p<.01 ;{ }^{* * *} p<.001$ 
Table 6 Sequential regression analysis for association of social support with physical activity

\begin{tabular}{|c|c|c|c|c|c|}
\hline & $B$ & SE B & $\beta$ & $R^{2}$ & $R^{2}$ change \\
\hline Step 1 & & & & .006 & .006 \\
\hline Gender & -.112 & .077 & -.049 & & \\
\hline BMI z-score & .009 & .032 & .009 & & \\
\hline Receive free or reduced lunch & .002 & .111 & .001 & & \\
\hline Parent's education & -.003 & .030 & -.004 & & \\
\hline Black & -.033 & .126 & -.011 & & \\
\hline Hispanic & -.143 & .111 & -.061 & & \\
\hline Other & -.010 & .118 & -.003 & & \\
\hline Step 2 & & & & .006 & .000 \\
\hline Food insecurity & .080 & .084 & .035 & & \\
\hline Step 3 & & & & $.130^{* * *}$ & $.124^{* * *}$ \\
\hline Instrumental support for PA & .093 & .013 & $.264^{* * *}$ & & \\
\hline Emotional support for PA & .062 & .016 & $.137^{* * *}$ & & \\
\hline Modeling of PA & .086 & .050 & .062 & & \\
\hline
\end{tabular}

Note: $B=$ Unstandardized beta coefficient; $S E B=$ Standard error for $B ; \beta=$ Standardized beta coefficient; $R^{2}=$ adjusted R-square; ${ }^{* * *} p<0.001$

about $13 \%$ of the variance in child's PA the previous week.

\section{Stratification by race and ethnicity}

Stratifying by race/ethnicity demonstrated some differences in the relationship between social support and the energy balance-related behaviors between racial/ethnic groups (Table 7). The association between all social support variables and FV intake was not significant in White children, but the models were significant for all other racial/ethnic groups. Emotional support was significantly associated with FV intake in Black children, but in no other group. Within significant models, family food culture was significantly associated with SSB intake in White children, home availability of those beverages was significantly associated with their intake only in Hispanics and Others, and instrumental support for healthy eating was significant only in Hispanic children. The association between social support and SSB intake, as well as social support and PA, were not significant in Black children. Instrumental support was significantly associated with a child's PA for Hispanic and Other, but not for White children. Emotional support for PA was significantly related to child's PA for both Hispanic and White children, and parental modeling of PA was significantly associated with PA behaviors only for White children.

\section{Discussion}

The sample of the TGEG study with third graders in Texas was largely composed of minority (Hispanic and nonHispanic Black) children. Of our sample, 47.2\% were overweight or obese, which is $13 \%$ higher than the U.S. prevalence for children 6-11 years of age [1]. The sample had high values for modeling of vegetable intake, modeling
PA, and emotional support for PA while most other variables had averages that fell in the third quartile of the range (Table 1). It is possible that parents in this sample felt capable and were already providing emotional social support for physical activity and were themselves participating in PA and consuming more vegetables, making modeling for these behaviors easier. However, instrumental support for PA was low as compared to the other scales, likely because it was the only scale measuring the number of days parents actually provided a specific type of support for their child. This study showed that while there was minimal difference in the various types of social support that girls and boys received, there were some meaningful differences between racial groups for certain types of social support. Of the racial and ethnic groups, Hispanic children reported substantially lower levels of home availability and accessibility of FV and emotional support for eating those foods, as compared to other racial/ethnic groups. Researchers previously identified lower levels of social support in this group [42, 60]. Our findings further highlight the importance of explicitly addressing these disparities in social support when developing interventions targeting Hispanic parents, potentially with additional skills training or increased intervention doses. There were also differences in parental social support based on the child's weight status; for example, overweight children received more emotional support for healthy eating. However, in contrast to previous studies that suggest that overweight and obese children receive less parental support for PA [61, 62], we found no differences in social support by child's weight status.

We found some other associations between parental social support and energy balance-related behaviors in children to be consistent with the literature, such as the association of instrumental [63-65] and emotional support 
Table 7 Association of social support with eating and physical activity, stratified by racial/ethnic group

\begin{tabular}{|c|c|c|c|c|c|c|c|c|c|c|c|c|}
\hline & White & & & Black & & & Hispanic & & & Other & & \\
\hline & $\overline{R^{2}}$ & $B$ & SE & $\overline{R^{2}}$ & $B$ & SE & $\overline{R^{2}}$ & $B$ & SE & $\overline{R^{2}}$ & $B$ & SE \\
\hline FV Intake & .112 & & & $.202^{* *}$ & & & $.126^{* * *}$ & & & $.189^{* *}$ & & \\
\hline Family food culture & & $.400 *$ & .154 & & $.691^{* * *}$ & .181 & & $.622^{* * *}$ & .125 & & $.421 *$ & .176 \\
\hline Instrumental support for healthy eating & & -.126 & .150 & & .125 & .209 & & .058 & .115 & & .227 & .166 \\
\hline Home availability and accessibility of FV & & -.007 & .096 & & -.106 & .120 & & .050 & .069 & & .154 & .101 \\
\hline Home availability of SSB & & -.303 & .325 & & .277 & .479 & & -.232 & .286 & & -.038 & .402 \\
\hline Emotional support for healthy eating & & -.027 & .097 & & $-.212^{*}$ & .107 & & -.027 & .058 & & -.012 & .091 \\
\hline Rules for eating & & -.016 & .134 & & .042 & .151 & & -.064 & .101 & & -.203 & .148 \\
\hline Modeling of vegetable intake & & -.116 & .424 & & 1.150 & .637 & & -.045 & .273 & & -.462 & .336 \\
\hline Modeling of SSB intake & & .102 & .241 & & -.528 & .352 & & .123 & .210 & & -.037 & .283 \\
\hline SSB Intake ${ }^{a}$ & $.143^{*}$ & & & .116 & & & $.103^{* *}$ & & & $.140^{*}$ & & \\
\hline Family food culture & & $.169 *$ & .073 & & $.188^{*}$ & .086 & & .087 & .059 & & -.010 & .081 \\
\hline Instrumental support for healthy eating & & -.039 & .072 & & .054 & .095 & & $.113^{*}$ & .055 & & .134 & .079 \\
\hline Home availability and accessibility of FV & & .033 & .045 & & -.010 & .055 & & -.021 & .033 & & -.025 & .046 \\
\hline Home availability of SSB & & .115 & .153 & & -.250 & .219 & & $.311^{*}$ & .137 & & $.374 *$ & .177 \\
\hline Emotional support for healthy eating & & .048 & .046 & & .016 & .049 & & .006 & .027 & & -.026 & .040 \\
\hline Rules for eating & & -.044 & .062 & & -.036 & .073 & & -.064 & .048 & & -.002 & .067 \\
\hline Modeling of vegetable intake & & -.015 & .200 & & .247 & .296 & & -.132 & .127 & & -.272 & .156 \\
\hline Modeling of SSB intake & & -.066 & .113 & & .071 & .169 & & .023 & .099 & & .075 & .124 \\
\hline PA last week ${ }^{a}$ & $.137^{* *}$ & & & .085 & & & $.173^{* * *}$ & & & $.188^{* * *}$ & & \\
\hline Instrumental support PA & & .008 & .031 & & $.085^{* *}$ & .030 & & $.115^{* * *}$ & .020 & & $.126^{* * *}$ & .029 \\
\hline Emotional support PA & & $.090 *$ & .038 & & .050 & .044 & & $.068^{* *}$ & .025 & & .045 & .035 \\
\hline Modeling of PA & & $.436^{* *}$ & .142 & & -.014 & .122 & & .038 & .071 & & .046 & .115 \\
\hline
\end{tabular}

Note: bold numbers are only used for models that are significant

$B=$ Unstandardized beta coefficient; $S E=$ Standard error for $B ; R^{2}=$ adjusted R-square; ${ }^{*} p<.05 ;{ }^{* *} p<.01 ;{ }^{* * *} p<.001$

${ }^{a}$ Covariates: gender, BMI z-score, free or reduced lunch, parent's education, food insecurity; not pictured

for PA with PA behavior in children [23, 66, 67]. Home availability of SSB was significantly associated with SSB intake, as seen in earlier research [30, 68, 69]. However, we noted differences from previous studies. It was unexpected that home availability and accessibility of FV was not associated with FV intake, as the association has been reported previously [29, 70-72]. Similarly, it was surprising to find no association of instrumental or emotional support for healthy eating, modeling vegetable intake, and modeling PA with the outcomes, as these types of support have been found to be associated with children's energy balancerelated behaviors in other populations [11, 71-75]. Family food culture was associated with FV intake, consistent with the literature that shows that increased family meals, the main component of family food culture, is associated with increased FV intake in children [76-79]. This was the only significant variable in the FV intake model and also the only child-reported social support; other studies have also found that various types of parental support reported by children were more associated with children's FV intake than the parent's perceptions of that same support [80-82].
We also found associations between some of the social support variables and behavioral outcomes that were in unexpected directions. In the case of the positive association of family food culture with SSB intake, it could be that the current family food culture is generally unhealthy [83, 84]. The unexpected associations could be a result of the influence of other variables, such as family cohesion $[85$, 86], or could demonstrate the child's rebellion against parents if the social support is perceived as a demand for behavior change [10]. It is possible that these unexpected findings may also indicate that parents are not the most important source for social support. In fact, many researchers report that peer social support might be more influential than parental support for many of these energy balancerelated behaviors [23, 32, 33, 87]. However, more research is needed in this area because parental social support has been identified as an important factor for energy balancerelated behaviors in children $[17,18]$.

Several social support variables were significantly associated with energy balance-related behaviors in certain groups but not in others, demonstrating potential differences in the relative impact of parental social support on 
children's subsequent behaviors. Given the differences, there could be implications for intervention development. For example, emphasizing emotional support for healthy eating in Black families may lead to greater changes in FV intake than a focus on other types of support. Given the importance of home availability of SSB on the SSB intake of Hispanic children, this should be one place of emphasis for interventions targeting Hispanic parents. However, an intervention with White parents with a similar target of reducing SSB intake may aim to alter the family food culture instead. For PA, interventionists may consider focusing on building instrumental and emotional support skills for PA among Hispanic parents. The insignificant models among Black children for both PA and SSB intake might indicate that other external factors in their environment [35-38] reduce the relative importance of parental social support for those energy-balance related behaviors and thus interventionists may consider looking elsewhere for the first point of intervention. As receiving free or reduced lunch at school was associated with FV intake in the overall model and the stratified model for Black children (data not shown), ensuring children have access to these programs might be more critical.

\section{Limitations}

Given the cross-sectional nature of our data, it is unclear how parental social support can causally impact children's eating and PA behaviors, as a determination about temporality could not be made and there remains the possibility of reverse causality. Our modeling variables and home availability of SSB were one item scales, limiting how well we could capture these constructs and the conclusions that can be drawn. We were limited in the information that could be accurately collected from the children, thus most variables relied on the parental report of social support or children's behavior. Lastly, we have not previously done extensive reliability and validity testing for some of the measures developed for this study, which may impact results. However, the Cronbach's alphas for the items in the scales were acceptable, indicating that the scales had good internal consistency. Despite these limitations, the findings offer greater insights into the relative association of different types of parental social support with energy-balance behaviors among low-income and diverse children.

\section{Conclusions}

Few studies have looked at parental social support and energy balance-related behaviors across racial and ethnic groups or made comparisons [39-42, 60]. This study is one of the few to compare the association of various types of parental social support and energy balance-related behaviors in children across racial and ethnic groups and provides evidence that the associations may differ between racial and ethnic groups. Future studies should attempt to assess the longitudinal relationship of parental social support with children's energy balance-related behaviors as well as the individual importance of each type of social support. Researchers developing interventions that impact parents to ultimately improve energy balance in children should take into account the types of social support most associated with the behavior of interest in their target population.

\begin{abstract}
Abbreviations
BMI: Body mass index; F\&V: Fruits and vegetables; PA: Physical activity; SES: Socioeconomic status; SNAP: Supplemental Nutrition Assistance Program; SSB: Sugar - sweetened beverages; TGEG: Texas Grow! Eat! Go!; WIC: The Special Supplemental Nutrition Assistance Program for Women, Infants, and Children
\end{abstract}

\section{Acknowledgements}

The authors would like to thank Carol K. Kohn, MS, ELS (D) for her professional editing services.

\section{Funding}

This work was supported by a pre-doctoral fellowship from the University of Texas School of Public Health Cancer Education and Career Development Program through the National Cancer Institute (R25CA57712 to N.I.H.) and by the Agriculture and Food Research Initiative from the USDA National Institute of Food and Agriculture, Integrated Research, Education and Extension to Prevent Childhood Obesity, A2101 (2011-68001-30138 to N.R., J.L.W., and A.E.E). The study was also partially funded by the Center for Health Promotion and Prevention Research as well as the Michael \& Susan Dell Foundation through resources provided at the Michael \& Susan Dell Center for Healthy Living, The University of Texas School of Public Health, Austin Regional Campus.

Availability of data and materials

The dataset supporting the conclusions of this article is available upon request by contacting Dr. Nalini Ranjit at Nalini.Ranjit@uth.tmc.edu.

\section{Author's contributions}

$\mathrm{NIH}$ contributed to the conception and design of this cross-sectional study, as well as to the analysis and interpretation of the data and writing of all sections of the manuscript. NR contributed to the acquisition of data, analysis and interpretation of the data and to writing and revising all sections of the manuscript. JLW (Primary Investigator) contributed to the conception and design of the overall Texas Grow! Eat! Go! Study, acquisition of data, and critical revisions of all sections of the manuscript. AEE contributed to the conception and design of the overall Texas Grow! Eat! Go! Study, acquisition of data, and the writing and revision of all sections of the manuscript. All authors gave final approval of this manuscript.

\section{Competing interests}

The authors declare that they have no competing interests.

\section{Consent for publication}

Not applicable.

\section{Ethics approval and consent to participate}

This research was approved by the University of Texas Health Sciences IRB, the Committee for the Protection of Human Subjects (\#HSC-SPH-10-0733) and the Texas A\&M University Institutional Review Board (\# IRB 2011-0012). Parents provided their written consent to participate, as well as written consent to let their child participate in the study. Students provided written assent at the time of data collection as well.

\section{Disclaimer}

The content is solely the responsibility of the authors and does not necessarily represent the official views of the National Cancer Institute or the National Institutes of Health.

\section{Author details}

${ }^{1}$ Center for Health Promotion and Prevention Research, The University of Texas Health Science Center at Houston (UTHealth) School of Public Health, 7000 Fannin St, Suite 2576E, Houston, TX 77030, USA. ${ }^{2}$ Michael \& Susan Dell 
Center for Healthy Living, The University of Texas Health Science Center (UTHealth) School of Public Health, Austin Regional Campus, Austin, TX, USA. ${ }^{3}$ Family \& Community Health, Texas A\&M AgriLife Extension Service, College Station, TX, USA

\section{Received: 30 June 2016 Accepted: 9 November 2016}

\section{Published online: 22 November 2016}

\section{References}

1. Ogden CL, Carroll MD, Kit BK, Flegal KM. Prevalence of childhood and adult obesity in the United States, 2011-2012. J Am Med Assoc. 2014:311:806-14

2. Sharma A, Grummer-Strawn L, Dalenius K, Galuska D, Anandappa M, Borland E, et al. Obesity prevalence among low-income, preschool-aged children-United States, 1998-2008. Morb Mortal Wkly Rep Surveill Summ. 2009;58:769-73.

3. Malik VS, Schulze MB, Hu FB. Intake of sugar-sweetened beverages and weight gain: a systematic review. Am J Clin Nutr. 2006;84:274-88.

4. Carlson JA, Crespo NC, Sallis JF, Patterson RE, Elder JP. Dietary-related and physical activity-related predictors of obesity in children: a 2-year prospective study. Child Obes. 2012;8:110-5.

5. Must A, Tybor D. Physical activity and sedentary behavior: a review of longitudinal studies of weight and adiposity in youth. Int J Obes. 2005;29:584-96.

6. Mikkilä V, Räsänen L, Raitakari O, Pietinen P, Viikari J. Longitudinal changes in diet from childhood into adulthood with respect to risk of cardiovascular diseases: the cardiovascular risk in young Finns study. Eur J Clin Nutr. 2004; 58:1038-45

7. Telama R, Yang X, Viikari J, Välimäki I, Wanne O, Raitakari O. Physical activity from childhood to adulthood: a 21-year tracking study. Am J Prev Med. 2005;28:267-73.

8. Kelder SH, Perry CL, Klepp K-I, Lytle LL. Longitudinal tracking of adolescent smoking, physical activity, and food choice behaviors. Am J Public Health. 1994:84:1121-6.

9. Craigie AM, Lake AA, Kelly SA, Adamson AJ, Mathers JC. Tracking of obesityrelated behaviours from childhood to adulthood: a systematic review. Maturitas. 2011;70:266-84.

10. Golan M, Crow S. Parents are key players in the prevention and treatment of weight-related problems. Nutr Rev. 2004;62:39-50.

11. Campbell KJ, Crawford DA, Ball K. Family food environment and dietary behaviors likely to promote fatness in 5-6 year-old children. Int J Obes. 2006:30:1272-80

12. Gustafson SL, Rhodes RE. Parental correlates of physical activity in children and early adolescents. Sports Med. 2006;36:79-97.

13. Trost SG, Sallis JF, Pate RR, Freedson PS, Taylor WC, Dowda M. Evaluating a model of parental influence on youth physical activity. Am J Prev Med. 2003;25:277-82.

14. Van der Horst K, Paw M, Twisk JW, Van Mechelen W. A brief review on correlates of physical activity and sedentariness in youth. Med Sci Sports Exerc. 2007;39:1241.

15. Patrick $H$, Nicklas TA. A review of family and social determinants of children's eating patterns and diet quality. J Am Coll Nutr. 2005;24:83-92.

16. Young EM, Fors SW, Hayes DM. Associations between perceived parent behaviors and middle school student fruit and vegetable consumption. J Nutr Educ Behav. 2004:36:2-12.

17. Pearson N, Biddle SJ, Gorely T. Family correlates of fruit and vegetable consumption in children and adolescents: a systematic review. Public Health Nutr. 2009;12:267-83

18. Beets MW, Cardinal BJ, Alderman BL. Parental social support and the physical activity-related behaviors of youth: a review. Health Educ Behav. 2010.

19. Edwardson CL, Gorely T. Parental influences on different types and intensities of physical activity in youth: a systematic review. Psychol Sport Exerc. 2010;11:522-35.

20. Arcan C, Neumark-Sztainer D, Hannan P, van den Berg P, Story M, Larson N. Parental eating behaviours, home food environment and adolescent intakes of fruits, vegetables and dairy foods: longitudinal findings from Project EAT. Public Health Nutr. 2007;10:1257-65.

21. Schoeppe S, Trost SG. Maternal and paternal support for physical activity and healthy eating in preschool children: a cross-sectional study. BMC Public Health. 2015:15:971.

22. Biddle SJ, Atkin AJ, Cavill N, Foster C. Correlates of physical activity in youth: a review of quantitative systematic reviews. Int Rev Sport Exerc Psychol. 2011:4: 25-49.
23. Springer AE, Kelder SH, Hoelscher DM. Social support, physical activity and sedentary behavior among 6th-grade girls: a cross-sectional study. Int J Behav Nutr Phys Act. 2006;3:8.

24. Nicklas TA, Baranowski T, Baranowski JC, Cullen K, Rittenberry L, Olvera N. Family and child-care provider influences on preschool children's fruit, juice, and vegetable consumption. Nutr Rev. 2001;59:224-35.

25. Davison KK, Jago R. Change in parent and peer support across ages 9 to $15 \mathrm{yr}$ and adolescent girls' physical activity. Med Sci Sports Exerc. 2009;41:1816-25.

26. Fisher JO, Mitchell DC, Smiciklas-Wright H, Birch LL. Parental influences on young girls' fruit and vegetable, micronutrient, and fat intakes. J Am Diet Assoc. 2002;102:58-64.

27. Nickelson J, Roseman MG, Forthofer MS. Associations between parental limits, school vending machine purchases, and soft drink consumption among Kentucky middle school students. J Nutr Educ Behav. 2010;42:115-22.

28. Spurrier NJ, Magarey AA, Golley R, Curnow F, Sawyer MG. Relationships between the home environment and physical activity and dietary patterns of preschool children: a cross-sectional study. Int J Behav Nutr Phys Act. 2008:5:31.

29. Hearn MD, Baranowski T, Baranowski J, Doyle C, Smith M, Lin LS, et al. Environmental influences on dietary behavior among children: availability and accessibility of fruits and vegetables enable consumption. J Health Educ. 1998:29:26-32

30. Ezendam NP, Evans AE, Stigler MH, Brug J, Oenema A. Cognitive and home environmental predictors of change in sugar-sweetened beverage consumption among adolescents. Br J Nutr. 2010;103:768-74.

31. van Ansem WJ, van Lenthe FJ, Schrijvers C, Rodenburg G, van de Mheen D. Socio-economic inequalities in children's snack consumption and sugarsweetened beverage consumption: the contribution of home environmental factors. Br J Nutr. 2014;112:467-76.

32. Duncan SC, Duncan TE, Strycker LA. Sources and types of social support in youth physical activity. Health Psychol. 2005;24:3.

33. Beets MW, Vogel R, Forlaw L, Pitetti KH, Cardinal BJ. Social support and youth physical activity: the role of provider and type. Am J Health Behav. 2006:30:278-89.

34. Watt TT, Martinez-Ramos G, Majumdar D. Race/ethnicity, acculturation, and sex differences in the relationship between parental social support and children's overweight and obesity. J Health Care Poor Underserved. 2012;23:1793-805.

35. Karpyn A, Manon M, Treuhaft S, Giang T, Harries C, McCoubrey K. Policy solutions to the 'grocery gap'. Health Aff (Millwood). 2010;29:473-80.

36. Day K. Active living and social justice: planning for physical activity in lowincome, black, and Latino communities. J Am Plann Assoc. 2006;72:88-99.

37. Sallis JF, Glanz K. The role of built environments in physical activity, eating, and obesity in childhood. Future Child. 2006;16:89-108.

38. Sallis JF, Glanz K. Physical activity and food environments: solutions to the obesity epidemic. Milbank Q. 2009;87:123-54.

39. O'Loughlin J, Paradis G, Kishchuk N, Barnett T, Renaud L. Prevalence and correlates of physical activity behaviors among elementary schoolchildren in multiethnic, low income, inner-city neighborhoods in Montreal, Canada. Ann Epidemiol. 1999:9:397-407.

40. Arredondo EM, Elder JP, Ayala GX, Campbell N, Baquero B, Duerksen S. Is parenting style related to children's healthy eating and physical activity in Latino families? Health Educ Res. 2006;21:862-71.

41. Adkins S, Sherwood NE, Story M, Davis M. Physical activity among AfricanAmerican girls: the role of parents and the home environment. Obes Res. 2004;12:38S-45.

42. Donnelly R, Springer A. Parental social support, ethnicity, and energy balancerelated behaviors in ethnically diverse, Low-income, urban elementary schoolchildren. J Nutr Educ Behav. 2015:47:10-8.

43. Bauer KW, Neumark-Sztainer D, Fulkerson JA, Hannan PJ, Story M. Familial correlates of adolescent girls' physical activity, television use, dietary intake, weight, and body composition. Int J Behav Nutr Phys Act. 2011;8:25.

44. Peterson MS, Lawman HG, Wilson DK, Fairchild A, Van Horn ML. The association of self-efficacy and parent social support on physical activity in male and female adolescents. Health Psychol. 2013;32:666.

45. Spears-Lanoix EC, McKyer EL, Evans A, McIntosh WA, Ory M, Whittlesey L, et al. Using family-focused garden, nutrition, and physical activity programs to reduce childhood obesity: the Texas! Go! Eat! Grow! pilot study. Child Obes. 2015:11:707-14.

46. Evans ARN, Hoelscher D, Jovanovic C, Lopez M, McIntosh A, Ory MG, Whittlesey L, McKyer L, Kirk A, Smith C, Walton C, Heredia NI, Warren JL. Impact of school-based vegetable garden and physical activity coordinated health interventions on weight status and weight-related behaviors of ethnically diverse, low-income students: study design and baseline data of 
the Texas! Grow! Eat! Go! (TGEG) cluster-randomized controlled trial. BMC Public Health. 2016;16:973.

47. Perry CL, Stone EJ, Parcel GS, Ellison RC, Nader PR, Webber LS, et al. School-based cardiovascular health promotion: the Child and Adolescent Trial for Cardiovascular Health (CATCH). J Sch Health. 1990;60:406-13.

48. Luepker RV, Perry CL, McKinlay SM, Nader PR, Parcel GS, Stone EJ, et al. Outcomes of a field trial to improve children's dietary patterns and physical activity: the Child and Adolescent Trial for Cardiovascular Health (CATCH). JAMA. 1996;275:768-76.

49. Aday LA, Cornelius LJ. Designing and conducting health surveys: a comprehensive guide. 3rd ed. San Francisco: Wiley; 2006.

50. Warner RM. Applied statistics: from bivariate through multivariate techniques: from bivariate through multivariate techniques. 2nd ed. Thousand Oaks: Sage; 2013.

51. Dave JM, Evans AE, Condrasky MD, Williams JE. Parent-reported social support for child's fruit and vegetable intake: validity of measures. J Nutr Educ Behav. 2012;44:132-9.

52. Hoelscher DM, Day RS, Kelder SH, Ward JL. Reproducibility and validity of the secondary level school-based nutrition monitoring student questionnaire. J Am Diet Assoc. 2003;103:186-94.

53. Larsen AL, McArdle JJ, Robertson T, Dunton G. Four dietary items of the School Physical Activity and nutrition (SPAN) questionnaire form a robust latent variable measuring healthy eating patterns. J Nutr Educ Behav. 2015; 47:253-8. e251.

54. Penkilo M, George GC, Hoelscher DM. Reproducibility of the school-based nutrition monitoring questionnaire among fourth-grade students in Texas. J Nutr Educ Behav. 2008:40:20-7.

55. Food Security in the U.S [Available at: http://www.ers.usda.gov/topics/foodnutrition-assistance/food-security-in-the-us/measurement.aspx]. Accessed 26 June 2016.

56. Clinical growth charts. [http://www.cdc.gov/growthcharts/dinical_charts.htm] Accessed 26 June 2016

57. Rhee KE, McEachern R, Jelalian E. Parent readiness to change differs for overweight child dietary and physical activity behaviors. J Acad Nutr Diet. 2014;114:1601-10.

58. Bauer KW, Laska MN, Fulkerson JA, Neumark-Sztainer D. Longitudinal and secular trends in parental encouragement for healthy eating, physical activity, and dieting throughout the adolescent years. J Adolesc Health. 2011:49:306-11.

59. Brunet J, Sabiston CM, O'Loughlin J, Mathieu ME, Tremblay A, Barnett TA, et al. Perceived parental social support and moderate-to-vigorous physical activity in children at risk of obesity. Res Q Exerc Sport. 2014;85:198-207.

60. Frenn M, Malin S, Villarruel AM, Slaikeu K, McCarthy S, Freeman J, et al. Determinants of physical activity and Low-Fat diet among Low income African American and Hispanic middle school students. Public Health Nurs. 2005;22:89-97.

61. Trost SG, Kerr LM, Ward DS, Pate RR. Physical activity and determinants of physical activity in obese and non-obese children. Int J Obes Relat Metab Disord. 2001:25:822-9.

62. Zabinski MF, Saelens BE, Stein RI, Hayden-Wade HA, Wilfley DE. Overweight children's barriers to and support for physical activity. Obes Res. 2003;11:238-46.

63. Beets MW, Pitetti KH, Forlaw L. The role of self-efficacy and referent specific social support in promoting rural adolescent girls' physical activity. Am J Health Behav. 2007;31:227-37.

64. Ornelas IJ, Perreira KM, Ayala GX. Parental influences on adolescent physical activity: a longitudinal study. Int J Behav Nutr Phys Act. 2007;4:1.

65. Prochaska JJ, Rodgers MW, Sallis JF. Association of parent and peer support with adolescent physical activity. Res Q Exerc Sport. 2002;73:206-10.

66. Bauer KW, Nelson MC, Boutelle KN, Neumark-Sztainer D. Parental influences on adolescents' physical activity and sedentary behavior: Iongitudinal findings from Project EAT-II. Int J Behav Nutr Phys Act. 2008;5:1.

67. King KA, Tergerson JL, Wilson BR. Effect of social support on adolescents' perceptions of and engagement in physical activity. J Phys Act Health. 2008;5:374.

68. Bere E, Sørli Glomnes E, te Velde SJ, Klepp K-I. Determinants of adolescents' soft drink consumption. Public Health Nutr. 2008;11:49-56.

69. Grimm GC, Harnack L, Story M. Factors associated with soft drink consumption in school-aged children. J Am Diet Assoc. 2004;104:1244-9.

70. Cullen KW, Baranowski T, Rittenberry L, Cosart C, Hebert D, de Moor C. Childreported family and peer influences on fruit, juice and vegetable consumption: reliability and validity of measures. Health Educ Res. 2001;16:187-200.
71. Reinaerts E, de Nooijer J, Candel M, de Vries N. Explaining school children's fruit and vegetable consumption: the contributions of availability, accessibility, exposure, parental consumption and habit in addition to psychosocial factors. Appetite. 2007:48:248-58.

72. Kristjansdottir AG, Thorsdottir I, De Bourdeaudhuij I, Due P, Wind M, Klepp K-I. Determinants of fruit and vegetable intake among 11-year-old schoolchildren in a country of traditionally low fruit and vegetable consumption. Int J Behav Nutr Phys Act. 2006;3:1.

73. Cullen KW, Baranowski T, Owens E, Marsh T, Rittenberry L, de Moor C. Availability, accessibility, and preferences for fruit, 100\% fruit juice, and vegetables influence children's dietary behavior. Health Educ Behav. 2003;30:615-26.

74. Sallis JF, Prochaska JJ, Taylor WC. A review of correlates of physical activity of children and adolescents. Med Sci Sports Exerc. 2000;32:963-75.

75. De Bourdeaudhuij I, Yngve A, Te Velde SJ, Klepp K-I, Rasmussen M, Thorsdottir l, et al. Personal, social and environmental correlates of vegetable intake in normal weight and overweight 9 to 13-year old boys. Int J Behav Nutr Phys Act. 2006:3:1.

76. Christian MS, Evans CE, Hancock N, Nykjaer C, Cade JE. Family meals can help children reach their 5 A Day: a cross-sectional survey of children's dietary intake from London primary schools. J Epidemiol Community Health. 2013;67:332-8.

77. Videon TM, Manning CK. Influences on adolescent eating patterns: the importance of family meals. J Adolesc Health. 2003:32:365-73.

78. Neumark-Sztainer D, Hannan PJ, Story M, Croll J, Perry C. Family meal patterns: associations with sociodemographic characteristics and improved dietary intake among adolescents. J Am Diet Assoc. 2003;103:317-22.

79. Fink SK, Racine EF, Mueffelmann RE, Dean MN, Herman-Smith R. Family meals and diet quality among children and adolescents in North Carolina. J Nutr Educ Behav. 2014;46:418-22.

80. Robinson-O'Brien R, Neumark-Sztainer D, Hannan PJ, Burgess-Champoux T, Haines J. Fruits and vegetables at home: child and parent perceptions. J Nutr Educ Behav. 2009:41:360-4.

81. Cook LT, O'Reilly GA, DeRosa CJ, Rohrbach LA, Spruijt-Metz D. Association between home availability and vegetable consumption in youth: a review. Public Health Nutr. 2015;18:640-8.

82. van Assema P, Glanz K, Martens M, Brug J. Differences between parents' and adolescents' perceptions of family food rules and availability. J Nutr Educ Behav. 2007;39:84-9.

83. Fulkerson JA, Story M, Neumark-Sztainer D, Rydell S. Family meals: perceptions of benefits and challenges among parents of 8-to 10-year-old children. J Am Diet Assoc. 2008;108:706-9.

84. Boutelle KN, Fulkerson JA, Neumark-Sztainer D, Story M, French SA. Fast food for family meals: relationships with parent and adolescent food intake, home food availability and weight status. Public Health Nutr. 2007;10:16-23.

85. Welsh EM, French SA, Wall M. Examining the relationship between family meal frequency and individual dietary intake: does family cohesion play a role? J Nutr Educ Behav. 2011;43:229-35.

86. Neumark-Sztainer D, Story M, Resnick MD, Blum RW. Correlates of inadequate fruit and vegetable consumption among adolescents. Prev Med. 1996;25:497-505.

87. Duncan SC, Duncan TE, Strycker LA, Chaumeton NR. A cohort-sequential latent growth model of physical activity from ages 12 to 17 years. Ann Behav Med. 2007;33:80-9.

\section{Submit your next manuscript to BioMed Central and we will help you at every step:}

- We accept pre-submission inquiries

- Our selector tool helps you to find the most relevant journal

- We provide round the clock customer support

- Convenient online submission

- Thorough peer review

- Inclusion in PubMed and all major indexing services

- Maximum visibility for your research

Submit your manuscript at www.biomedcentral.com/submit
Biomed Central 